\title{
EL SISTEMA LAKU MAPUCHE-PEWENCHE Y LOS LIIMITES ÉTNICOS DEL PARENTESCO
}

\section{The Mapuche-Pewenche laku System and the Ethnic Boundaries of Kinship}

\section{MARCELO GONZÁLEZ G. *}

Fecha de recepción: 15 de enero de 2018 - Fecha de aprobación: 26 de junio de 2018

\section{Resumen}

Este artículo aborda el sistema "tradicional" de denominación mapuche, fundado en la transferencia de nombres propios entre generaciones alternadas, indagando en las maneras contemporáneas en que persiste en las comunidades mapuchepewenche de Alto Biobío, en los Andes del centro-sur de Chile. A través de una revisión de la literatura referida al "nombre" entre los mapuche, contrastada con información recabada durante tres meses de observación participante en dos comunidades de Alto Biobío, elaboramos una reflexión con respecto a la transformación que ha sufrido el sistema, la que habría sido gatillada fundamentalmente por la intensificación de las relaciones coloniales llevadas a cabo por el Estado chileno, y debido a una difundida percepción indígena con respecto a la criminalización del movimiento mapuche contemporáneo. Esta reflexión nos permite, a modo de conclusión, desvincular el parentesco del ámbito procreativo, para asociarlo de plano con una dimensión política y, más específicamente, étnica.

Palabras clave: Mapuche-pewenche; Sistemas de denominación; Parentesco; Etnicidad.

\section{Abstract}

This article approaches on Mapuche 'traditional' naming system, founded on transferring proper names between alternate generations, exploring how it currently persists among Mapuche-Pewenche communities from Alto Biobío, in the southcentre Andes of Chile. Reviewing what different scholars have proposed on this naming system, and comparing this views with the information I recollected during three months of participant observation in Alto Biobío, I reflect on the transformation the system has suffered, which would have been triggered by the intensification of the colonial relations carried out by the Chilean State, and due to the general indigenous perception about the criminalization of contemporary Mapuche political organizations. Eventually, this reflection allows us to detach kinship from procreation, linking it instead to politics and, more specifically, to ethnicity.

Keywords: Mapuche-Pewenche; Naming systems; Kinship; Ethnicity.

* Dr. en Antropología Social. Profesor asistente, Programa de Antropología Pontificia Universidad Católica de Chile, Santiago, Chile. El artículo contó con el apoyo del Centro de Estudios Interculturales e Indígenas (CIIR, Conicyt/Fondap/15110006). Correo-e: magonzalezg@uc.cl 
En una tarde extrañamente cálida de mayo, hace ya algunos años, me encontraba solo en la casa de la familia donde hospedaba en la comunidad de Cauñikú, en un sector encallado en la cordillera de los Andes de la VIII región de Chile, llamado Alto Biobío, donde habitan principalmente personas que se auto-identifican como pewenche. Todos los demás se encontraban en Ralco, un pequeño pueblo a una hora de distancia en auto, que funciona como el centro administrativo del sector. La absoluta calma que caracteriza usualmente al lugar fue interrumpida súbitamente con la aparición de una impetuosa anciana. Junto con saludarme en chedungun, la lengua del lugar, mientras se movía buscando algo por todo el recinto, me preguntaba insistentemente, esta vez en castellano, si yo había visto a su "mamá". Era la primera vez que veía a esta mujer, pero de todas formas su pregunta me pareció algo extraña, en tanto por una cuestión meramente etárea me parecía obvio que era difícil que su madre pudiese aún encontrarse con vida. Entonces le pregunté: “¿Quién es su mamá? ¿cómo se llama?" Notando mi desconcierto, la mujer hizo caso omiso a mis preguntas. Tranquilizó su búsqueda, se sentó sobre una banca, y comenzó entonces a enfocarse en saber quién era yo, y qué era lo que me encontraba haciendo, solo, en ese lugar. Conversamos un par de minutos, mientras empecé a notar que la quietud momentánea que había gatillado mi pregunta comenzaba a disiparse. De improviso y rápidamente, entonces, la mujer se puso de pie y, en una nueva muestra de su inquietud, se decidió rápidamente a partir. Antes de hacerlo, eso sí, me pidió encarecidamente un favor: "¿podría decirle a mi mamá que estuve aquí y que voy a volver mañana?" "Está bien"-le respondí- "pero no puedo hacerlo si no sé quién es su mamá". La mujer me miró detenidamente, suspiró, y me dijo: "María", para luego darse media vuelta y dejar rauda el lugar.

María, la dueña de la casa donde me encontraba hospedando, era una mujer de mediana edad, aproximadamente treinta años más joven que Juana. Inicialmente supuse que la anciana la llamaba "mamá" en una señal de cariño o consideración, es decir, que empleaba el término metafóricamente, en un intento por hacer calzar sus significantes con mi propio marco cultural, y no le di más vueltas al asunto. Sin embargo, cuando horas más tarde María volvió y le entregué el mensaje, su reacción me obligó a reconsiderar mi primera explicación. María me miró y me dijo simple y sucintamente: "ah, vino la Juana... mi hija".

Este artículo tiene dos objetivos. En primer término intenta mostrar cómo es posible que Juana sea, realmente, la hija de María. Para hacer esto, describiré el sistema "tradicional" de denominación mapuche, el lakutun, que en la actualidad parece subsistir, como era practicado antaño, solamente en las comunidades mapuche-pewenche de Alto Biobío. El segundo objetivo de este artículo es proponer que, en el contexto de una intensificación de las relaciones entre los mapuche-pewenche con el Estado chileno, a contar de las décadas de 1980 con la apertura de un camino (Bonelli \& González Gálvez, 2018), y 1990 con la construcción de dos grandes represas (Namuncura, 1999), el sistema laku puede haber perdurado debido a que permite delinear, y crear intencionadamente de manera clara y precisa, un límite étnico (sensu Barth, 1969). Es sabido que el empleo táctico, con fines político-económicos u otros, de las relaciones de alianza y parentesco ritual ha sido reportado en muchas épocas y contextos etnográficos distintos (Carsten, 2004; 
Carsten \& Hugh-Jones, 1995; Lévi-Strauss, 1969; Leinaweaver, 2007; Sahlins, 2013; Viveiros de Castro, 1992), lo que también es válido para poblaciones mapuche (Foerster, 1980; Isla, 2018). No obstante, la particularidad del caso que observamos se relaciona con que un sistema que parece tener históricamente dos finalidades claras, a saber la replicación de un conjunto de posiciones sociales finitas dentro de un mismo grupo residencial (lov) (Foerster \& Gündermann, 1993; Mauss, 1985) y el establecimiento de alianzas con otros grupos residenciales (Isla, 2018), dadas determinadas circunstancias históricas, junto a un énfasis mapuche en la co-residencia (Bonelli, 2014; González Gálvez, 2016, 2015), se transforma para apoyar la delimitación entre un colectivo étnico pewenche, que es distinto a un colectivo "otro" colonial que atenta contra la integridad del mismo (signado con el término winka, "no-mapuche").

Para conseguir los objetivos recién mencionados, abordaré primero en términos generales quienes son los mapuche-pewenche, para posteriormente describir el sistema y el ritual del lakutun, mostrando sus potenciales vínculos y diferencias con el compadrazgo, institución a la que a veces equivocadamente se homologa, y que comúnmente es considerada como una relación central y multifuncional en Latinoamérica (Bolton \& Mayer, 1977; Gudeman, 1971; Leinaweaver, 2007; Woodrick, 1995). Posteriormente, desarrollaré mi propia comprensión del funcionamiento del lakutun en la actualidad, y las razones por las que creo es aún muy importante para los mapuche-pewenche de Alto Biobío, mientras en otros contextos geográficos mapuche sus implicancias rituales y sociales parecen haberse desvanecido, y el término laku es simplemente homologado al caste- llano "tocayo" (cf. Coña, 2002; Course, 2011; Latcham, 1924).

\section{Los mapuche-pewenche y el lakutun}

Los pewenche conforman una identidad territorial vinculada a un nicho ecológico específico, que usualmente se considera incluida, política y culturalmente, dentro de un colectivo denominado como "mapuche", asumido como el pueblo indígena más numeroso de Chile. El etnónimo pewenche significa literalmente "gente del pewen" (araucaria araucana), árbol cuyo fruto, el piñon o nguillíu en chedungun, es esencial a su dieta. Actualmente habitan las zonas andinas del centro-sur de Chile, esencialmente las comunas de Alto Biobío y Lonquimay, en la VIII y IX regiones de Chile respectivamente. Específicamente en Alto Biobío, los asentamientos indígenas se encuentran organizados territorialmente a lo largo de las riberas y montañas que rodean a los ríos Queuco y Biobío. Los datos para la realización de este trabajo fueron recolectados en una comunidad vecina a cada río: Cauñikú y Callaqui, respectivamente.

Hace algunos años los mapuche-pewenche alcanzaron notoriedad internacional debido a la construcción de dos centrales hidroeléctricas en su territorio, lo que dio como resultado la inundación y relocalización de parte importante de las comunidades de la cuenca del Biobío (Fuenzalida, 2010; Namuncura, 1999). En los últimos años, aun cuando los mapuchepewenche se consideran ampliamente como "mapuche", han comenzado a emplear con mayor insistencia el término pewenche para diferenciarse de otros grupos mapuche del valle o de la costa Pacífica. De acuerdo a los testimonios de la gente, esto muchas veces se 
debe a la reputación que, se supone, han adquirido los mapuche dentro de algunos sectores de la sociedad chilena, siendo estigmatizados como "terroristas" debido a las acciones que algunos grupos realizan en pos de la recuperación de sus territorios ancestrales (Correa \& Mella, 2010; Fernández \& Ojeda, 2015).

Cuando consideramos los estudios antropológicos sobre el pueblo mapuche en general, las investigaciones centradas en el parentesco han gozado históricamente de un lugar de privilegio, posiblemente en sintonía con una preocupación inicial, desarrollada en la etnología de las tierras bajas tropicales sudamericanas, por la estructura social (Maybury-Lewis, 1979; Rivière, 1981) y posteriormente por las dinámicas y filosofías de construcción de los grupos locales (Overing \& Passes, 2000; Viveiros de Castro, 2001). Importantes trabajos han sido dedicados a este tema, desde descripciones de los esquemas de descendencia (Faron, 1956, 1961a, 1961b) hasta enfoques que intentan explicar la organización de la sociedad poniendo énfasis sobre las reglas de alianza (Foerster, 1980, 2004; Stuchlik, 1976), y llegando contemporáneamente a aproximaciones que privilegian una descripción de la constitución personal y relevan la importancia de la co-residencia (Bonelli, 2014; Course, 2005, 2011; González Gálvez, 2016; Isla, 2018). En este contexto general, se ha puesto históricamente gran atención en las prácticas de denominación (Augusta, 2002; Melville, 2016; Foerster \& Gündermann, 1993; Foerster, 2004, 2010; Silva, 1984), cuestión que ha probado ser altamente informativa en otros contextos etnográficos (Bamberger, 1974; Bodenhorn \& Von Bruck, 2006; Suzman, 1994; Thomson, 1946). Básicamente, los intentos de comprender esta dimensión, entre los mapuche, han intentado develar algún tipo de regula- ridad entre los nombres, a fin de aproximar la evidencia hacia algún tipo de formación social fundada en la descendencia. Así, por ejemplo, inicialmente el misionero Augusta (2002 [1907]) propuso que el sistema de denominación mapuche se basaba en la transmisión de una cierta raíz que funcionaba de manera equivalente a un apellido (kumpen), más la adición de un sufijo o prefijo que derivaba de algún rasgo específico personal del niño a ser nombrado. Es decir, se trataba de un sistema regido por la descendencia, pero que dejaba lugar a la unicidad irreductible de cada persona. Algunos años después, uno de los fundadores de la antropología chilena, Ricardo Latcham (1924), empleó la aparente ausencia de regularidades entre los nombres masculinos del mismo linaje para afirmar la existencia de un sistema de descendencia matrilineal entre los mapuche.

Con posterioridad, con la verificación etnográfica de la descendencia patrilineal entre los mapuche (Faron, 1956, 1961a, 1961b), las preocupaciones en torno a las prácticas de denominación se vieron renovadas. Dentro de este contexto, el trabajo fundamental al respecto es el de Foerster \& Gündermann (1993), quienes proponen la existencia del sistema laku. En términos simples, este sistema se basa en la idea de que una persona de determinada generación entregaría su nombre a una persona de la generación de sus nietos, saltándose a la generación inmediatamente siguiente. Esta cuestión encuentra su fundamento en la significación del término laku, que es un vocablo recíproco que en la terminología de parentesco mapuche se utiliza para las posiciones de abuelo y nieto, y ya había sido previamente esbozada por el mismo Foerster: "Ego recibe su gui [nombre] de su abuelo paterno [laku] y se lo entrega al hijo de su hijo [laku]" (1980, p. 
61). Es decir, los nombres eran transmitidos a través de un mecanismo de generaciones alternadas (Foerster, 2010)2. De manera importante, aunque el sistema de denominaciones tiene como finalidad la afirmación de las unidades de descendencia (Foerster \& Gündermann, 1993), Foerster nota que esta situación puede tener cierta flexibilidad, admitiendo que el esquema de generaciones alternadas es una suerte de regla prescriptiva, pero que puede existir eventual- mente una relación de laku entre sujetos de generaciones sucesivas, entre sujetos de la misma generación si quien da su nombre es un adulto, y entre sujetos de distinto linaje si existe una relación que requiera ser afirmada entre el donador del nombre y el padre del receptor del nombre (Foerster, 1980). Esta situación es similar a la que me fue posible observar, aunque sin la preeminencia clara de ninguna regla, como veremos más adelante.

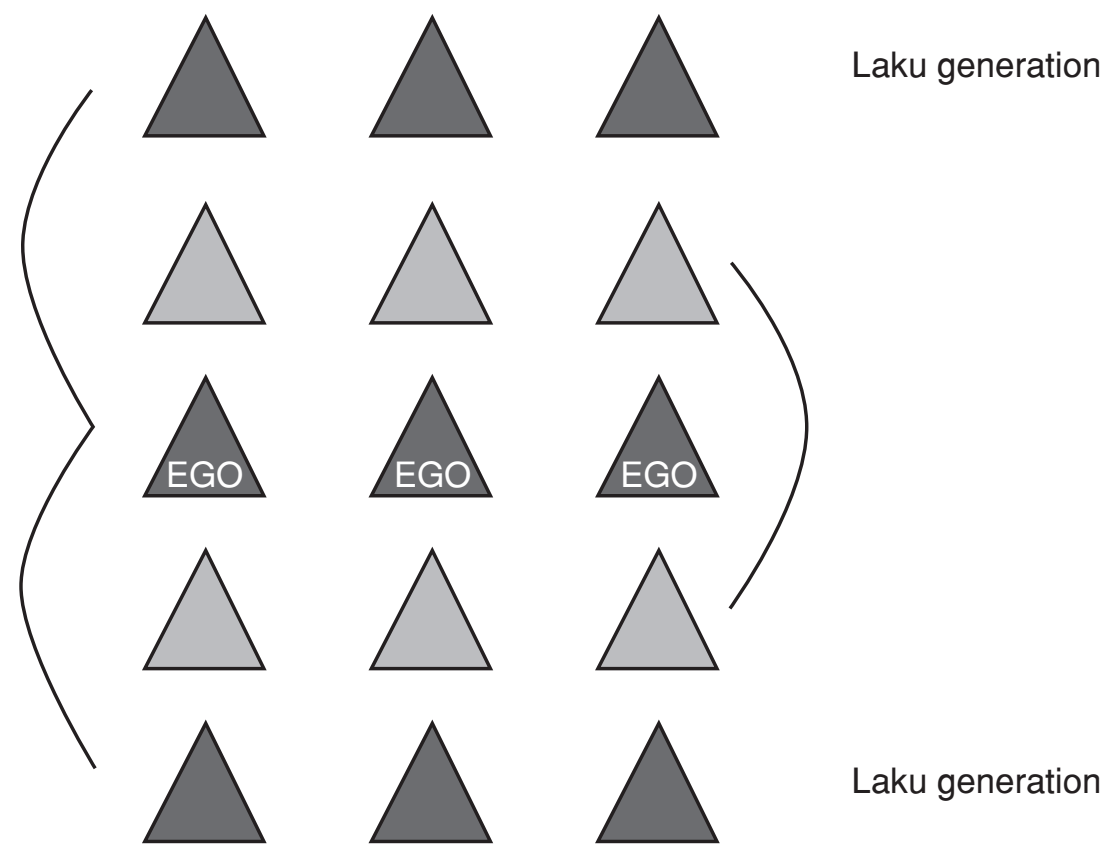

Figura 1: Comprensión del sistema laku (según Foerster \& Gündermann, 1993) (Elaboración propia) 
Además de esto, el sistema laku tendría una particularidad de género que resulta de la regla tradicional mapuche de alianza matrilateral y residencia virilocal. Así, mientras los nombres de los hombres tenderían a permanecer dentro de grupos de linaje específicos, situados territorialmente, los nombres femeninos tenderían a circular entre linajes (Foerster, 1980; Foerster \& Gündermann, 1993) ${ }^{3}$. Siguiendo este esquema, los mapuche habrían contado tradicionalmente con un conjunto finito de nombres propios, que hasta cierto punto se corresponderían con un conjunto finito de estatus que debían ser cumplidos dentro del linaje. De hecho, de cierta forma, este conjunto de nombres propios habría definido y dado forma al linaje, lo que es coincidente con lo que atestigua al respecto Inez Hilger (2015), en tanto sería extremadamente raro entregar nombres que no hayan estado en la familia "hace mucho tiempo". Aun cuando la existencia del linaje como principio de estructuración social se encuentra ampliamente cuestionada en el caso de los mapuche (Course, 2011; Stuchlik, 1976), la idea de que los nombres encuentran cierto grado de finitud a un colectivo social tiene sentido con respecto a mi experiencia en Alto Biobío, especialmente considerando que los nombres encarnarían una serie de cualidades indispensables para el cumplimiento de roles específicos, vitales para la vida social del grupo local (como habilidades oratorias, fuerza física, y capacidad de observación, que serían importantes, respectivamente, para los roles de liderazgo, producción de alimentos, y sanación) ${ }^{4}$.

Entre los mapuche-pewenche, la subsistencia del sistema laku implica la coexistencia de dos sistemas de denominación. Por una parte uno oficial-legal, que se encuentra registrado de acuerdo a las normas chilenas y que usualmente consta de dos nombres propios (a veces uno, a veces tres o más) y dos apellidos. Por otra, el chegüi (lit. che: persona, gente; güi: nombre), el nombre transferido a través del sistema laku, y que en su uso predomina en las relaciones cotidianas de Alto Biobío5. Para establecer la relación de laku, usualmente se espera a que los niños demuestren alguna de sus características personales, y se le solicita a quien tenga un nombre propio que coincida con esas características, que le entregue su nombre al niño. Otra manera de proceder, fundamentalmente en el pasado, habría sido realizando una cuidadosa "lectura" de la placenta, con lo que podía determinarse el destino del niño, y con ello un donador/nombre adecuado para él ${ }^{6}$. En otras ocasiones, el nombre se habría elegido por simple decisión paterna (Hilger, 2015) o para establecer relaciones socialmente deseables ${ }^{7}$, aunque siempre se explicita que el ideal es que el vínculo laku una a un niño con el padre de su padre (Isla, 2018). Cuando la persona mayor accede a entregar su nombre, él y los padres del niño/a acuerdan una fecha para realizar la ceremonia en que se establece el vínculo de laku. El nombre de esta ceremonia es lakutun (aprox. "hacerse laku") si quien recibirá el nombre es un niño, y katankawiñ (aprox. "reunión para perforar") en el caso de una niña. La diferencia principal entre ambas ceremonias es que, en la última, una parte importante del ritual la constituye la perforación de las orejas de la niña, a fin de ponerle aros. Para la realización del ritual se especificaba que quien entregaba su nombre debía proveer un animal, de preferencia un cordero, y tanto él como los padres del niño debían proveer chavid, un espeso líquido que se hace a partir de los piñones fermentados de la araucaria araucana (Hilger, 2015). 
De acuerdo a nuestros distintos interlocutores en Alto Biobío, la ceremonia se suele realizar muy temprano en la mañana. Ambos laku deben entrecruzar sus brazos mirando hacia el este, mientras un líder comunitario (i.e. lonko, lit. "cabeza") pronunciaba un discurso sellando el vínculo entre donante y receptor. Durante este discurso se ruega a diversas entidades no-humanas, y también se realizan pinturas faciales que visibilizarían un principio de identidad común entre las dos personas directamente involucradas en el lakutun (Isla, 2018). Un asunto que nos parece de especial relevancia, es que durante el sacrificio del animal que se realiza durante el rito, se vierte parte de la sangre en la tierra, haciendo saber que es la misma tierra donde se ha enterrado anteriormente la placenta del niño (y en algunos casos del adulto donador del nombre) (Hilger, 2015) ${ }^{8}$. Esta sección del ritual articularía dos partes esenciales de la composición de la persona pewenche, según ésta ha sido descrita por Cristóbal Bonelli (2012, 2014; Course, 2011; Isla, 2018). De alguna forma, durante el lakutun se superpone el am (aprox. "principio de subjetividad") de la persona, metonimizado en la placenta enterrada, que a su vez es metáfora del "enraizamiento del sujeto", con el püllü (aprox. "fuerza vital") que comparten todos los seres que habitan un lugar, encapsulado en la sangre del animal sacrificado. Esto hace evidente que la singularidad de la persona está vinculada necesariamente a un conjunto relacional que constituye esa singularidad (Bonelli, 2014; González Gálvez, 2015).

Una vez establecido el vínculo, los sujetos directamente involucrados -que comienzan a denominarse recíprocamente laku- deben respetar diversas obligaciones y deberes mutuos. De acuerdo a Hilger (2015), esto se debe a que el lakutun transforma al donador del nombre en padre del niño. En desacuerdo con esta idea, José Isla (2018) señala que se genera una suerte de identidad entre ambos laku. Es decir, a partir de compartir el mismo nombre, pasarían a ser, al menos metafóricamente, la misma persona. El ejemplo que entrega Isla para sostener esta impresión es bastante ilustrativo. Comienza cuando se entera que uno de sus amigos pewenche, de entre 30 y 40 años, era llamado "el viejo" por unas tías que eran mucho mayores que él. Esto se debía a que el hombre en cuestión era laku de su abuelo, quien a su vez era el difunto padre de las tías. Ambos hombres compartían un nombre, y por lo mismo una posición, y más aún, eran el mismo sujeto en términos parentales. El amigo de Isla era, simultáneamente, el sobrino y el padre de sus tías. Este descubrimiento permite desafiar la comprensión de Inez Hilger, que parece fusionar el lakutun con el bautismo católico. Un rasgo importante para este cuestionamiento radica en que, en el bautismo, el principio de identidad se genera entre padres y padrinos en relación al niño, y se señala por el mutuo tratamiento que se da entre los primeros de "compadres". En el caso del lakutun, el término mutuo de tratamiento tiene lugar entre quien entrega el nombre y el niño, y de la misma forma entre ellos tiene lugar el principio de identidad. En el caso del bautismo hay un principio de identidad intrageneracional, mientras que en el lakutun es intergeneracional, lo que suprime cualquier asimetría etárea entre ambos laku, y es consistente con la manera en que los mapuche comprenden el poder, negando el establecimiento de la autoridad (Melville, 2016). Esta situación además es consistente con la manera en que, según Course, el parentesco mapuche consideraría permanentemente el conjunto de posiciones virtuales que puedan existir entre un 
par dado de sujetos, por más que contingentemente se actualice una posición en específico: "es la interacción entre estas diversas maneras de relacionarse con diversos 'otros', la que constituye los diversos 'caminos' posibles que la persona mapuche toma durante su vida, y también los 'caminos' imaginados que permanecen no tomados, pero siempre presentes" (2005, p. 17; traducción propia).

Más allá de los distintos aspectos aquí señalados, existe una opinión extendida con respecto a que el sistema laku otorgaría estabilidad estructural a la sociedad pewenche (Foerster, 1980, 2004, 2010; Foerster \& Gündermann, 1993; Isla, 2018). De hecho, se llega a plantear que el mismo lakutun constituiría "el fundamento ritual para la constitución del grupo residencial" (Isla, 2018, p. 337). Esto se daría en base a la regla patrilineal tras el sistema, lo que haría que los nombres circulen cíclicamente al interior de los "linajes", "lov" o "grupos residenciales" (cualquiera sea la entidad organizacional que se elija relevar), haciendo que estos se encuentren conformados por cuatro generaciones que se comprimen en dos, debido a la identificación entre generaciones alternadas ${ }^{9}$. Esta circulación de nombres permitiría la existencia de entidades sociales claramente delimitadas, que, al mismo tiempo, se conectarían por medio de la circulación de nombres femeninos, permitiendo un sentido de extensión (o imaginación) grupal mayor. Además, gracias a la misma compresión del tiempo generacional, esta imaginación tiene una interesante arista supratemporal. Como me dijo una vez un anciano pewenche: "la importancia del laku es que después que yo me muera voy a permanecer aquí, todo gracias a haber entregado mi nombre". El sistema laku dotaría así a la sociedad pewenche de un principio de conti- nuidad cíclica, perpetuando una obra inmutable llena de roles que deben ser ejecutados, y cambiando solamente el elenco físico que los despliega (Mauss, 1985).

\section{Transformaciones externas de la vida mapuche-pewenche}

Antes de continuar, es preciso reseñar, muy someramente, la historia de relaciones coloniales que han afectado a los mapuche, y que, en mi opinión, podrían haber colegido en la disminución de la presencia del sistema laku a nivel general, y en su torsión étnica en los últimos años entre los pewenche de Alto Biobío. Ya hemos señalado que este sector se encuentra encallado en las montañas donde nace el río Biobío, que ha jugado históricamente un rol muy importante en las relaciones entre los mapuche, españoles y posteriormente chilenos. Funcionó como frontera de facto entre el imperio español y el territorio autónomo mapuche al menos desde 1598, luego de la histórica victoria mapuche frente al ejército hispano en la batalla de Curalaba (Millalén, 2006), y fue declarada como frontera oficial en un parlamento hispano-mapuche de 1641. En el intertanto, la frontera sirvió para el establecimiento de fluidas relaciones, que incluían relaciones políticas, económicas, y de evangelización, que eran practicadas en una explícita simetría social (Foerster, 2004; Zavala, 2008). En el caso específico de los pewenche, habrían participado de estas relaciones interétnicas, que incluían a diversas identidades territoriales indígenas, sin necesariamente establecer una alianza duradera entre ellas (Villalobos, 1989).

El estatus del río permaneció así hasta el siglo XIX, cuando comenzó a mutar con la instaura- 
ción del Estado Chileno, y debido a la creciente ejecución de diversas hostilidades producidas justamente por la necesidad de darle integridad territorial al Estado. Con este fin, en la década de 1860 comenzó la ocupación militar del territorio mapuche, que en 1882 tuvo una operación militar directamente dirigida a la zona pewenche, la "Expedición a la cordillera de la Araucanía", que tenía como fin establecer soberanía y evitar la entrada argentina a este sector (Fuenzalida, 2010). Estas campañas se vieron coronadas con la instauración de la "Radicación de indígenas", realizada entre los años 1883 y 1927 . En el marco de este proceso, las poblaciones del lugar fueron ubicadas de manera arbitraria en reservaciones, literalmente en "reducciones", en consideración de las tierras que supuestamente ocupaban "en realidad". Con este proceso, a nivel general, el Estado reconocía la propiedad consuetudinaria de tan solo un $10 \%$ del territorio mapuche ancestral, exactamente 510.386 hás de un total aproximado de al menos 5.000.000 hás (González, 1986). Luego, la escasez de tierras, y la creciente presión demográfica sobre ellas, provocó un extendido proceso de migración campo-ciudad durante todo el siglo $X X$. Los mapuche, que aún permanecen en los remanentes de sus territorios ancestrales, han debido lidiar con la expansión neoliberal de la industria forestal, y con la expansión asistencial y subsidiaria desarrollada desde el retorno a la democracia chilena en 1990.

Todos estos procesos, en su conjunto, han generado la emergencia de diversos movimientos mapuche que intentan resistirse ante las posiciones que intentan dominarlos. La respuesta estatal a esta reacción mapuche ha redundado en la criminalización del movimiento, lo que se escenifica en que desde el año 2000 más de un centenar de mapuche han sido encarcelados por acciones relacionadas con reivindicaciones territoriales, entre los cuales una cincuentena han sido acusados y procesados bajo una ley antiterrorista heredada de la dictadura militar (Correa \& Mella, 2010). Como ya señalamos, un conflicto de gran trascendencia simbólica en este marco se generó en torno a la instauración de dos represas en Alto Biobío (Namuncura, 1999). Más allá de esto, y en vista a la consideración que los mismo pewenche mantienen de la abierta criminalización con que tratan los medios de comunicación de masas al movimiento mapuche contemporáneo (Fernández \& Ojeda, 2015), la empatía que sentían antaño en la lucha contra la instalación de las represas parece ser casi inexistente en la actualidad. Esto genera una permanente y abierta diferenciación entre la gente pewenche y el "resto" de población mapuche. Así, por ejemplo, como me decía un amigo, hay un sentido en que los pewenche se consideran "mapuche", en tanto "índígenas"10, pero otro en que se consideran "pewenche", distintos de los "mapuche", a fin de marcar una diferencia con "esa otra gente, que anda haciendo esas cosas [acciones criminalizadas/criminales]". En mi impresión, es muy probable que la situación contemporánea de criminalización masiva de lo mapuche haya fortalecido una adscripción étnica pewenche, en desmedro de lo que sucedía tan solo algunos años en el pasado, donde la adscripción étnica "mapuche" era totalmente mayoritaria en la región ${ }^{11}$. Asímismo, es muy probable que los pewenche hayan empleado lo que tenían a mano para realizar este fortalecimiento: la particularidad de la adaptación a la vida de montaña, el uso fundamental del piñón, y, especialmente, el sistema laku. 


\section{El sistema laku en la actualidad}

En mi propia experiencia etnográfica, los nombres mapuche se transmiten a través de un sistema laku, que en general se basa en muy pocas reglas totalmente necesarias. De hecho, la única regla que parece deber cumplirse obligatoriamente es que la donación de nombres debe tener lugar entre personas del mismo género. En referencia a los donadores de nombre, la gente sostiene que, de preferencia, debe tratarse de una persona mayor, porque debido a la sabiduría que han acumulado durante sus vidas, gozan de mayor responsabilidad y respeto hacia los otros $^{12}$. Sin embargo, también podría darse el caso de que un donador pueda ser un joven que sea considerado especialmente respetuoso. La razón para esto es que el donador debe honrar la relación mutua y recíproca que establecerá con el niño a quien entregará su nombre. De manera muy importante, la gente afirma que en la actualidad no existe ninguna restricción filial para entregar y buscar un nombre, por lo que éste podría otorgarse, teórica y prácticamente, incluso a una persona no-mapuche. Esta situación también era observable antaño, aunque supuestamente solo en el caso de gente especialmente importante con quien pudiese establecerse una alianza estratégica (Isla, 2018). En este sentido, actualmente el sistema laku ya no tendría la finalidad principal de comprimir el grupo residencial a dos generaciones, sino, en cambio, funcionaría para extender el grupo de parientes tácticamente de manera generalizada. En otras palabras, liberado de su énfasis patrilineal, el sistema laku permite una sociedad donde virtualmente todos pueden ser parientes de todos: una sociedad de parientes. Así, más que estar obsesionados con la mantención del linaje, o con la afirmación de una identidad, siguiendo a Viveiros de Castro (2001) creemos que es posible plantear que lo que se lograría a través del sistema laku es la atracción de una alteridad, signada por la "afinidad potencial", a través de su reducción ritual contingente, escenificada en el lakutun, "hacerse laku".

De acuerdo a lo que señala la gente en la actualidad, una vez establecido el acuerdo entre padres y donador, es que se realiza el lakutun, de una manera similar a la descrita en la primera sección de este artículo. Lo interesante, es que de este ritual emergería abiertamente un principio de similitud entre los sujetos implicados en la donación de nombres. De hecho, luego del lakutun ambos laku son la misma persona, un único nombre mapuche. Ambos comparten las mismas características personales, y de modo trascendental, también comparten las mismas relaciones de parentesco. En estricto rigor, ambos ocupan la misma posición en un espacio social tridimensional, graficado en la Figura 2.

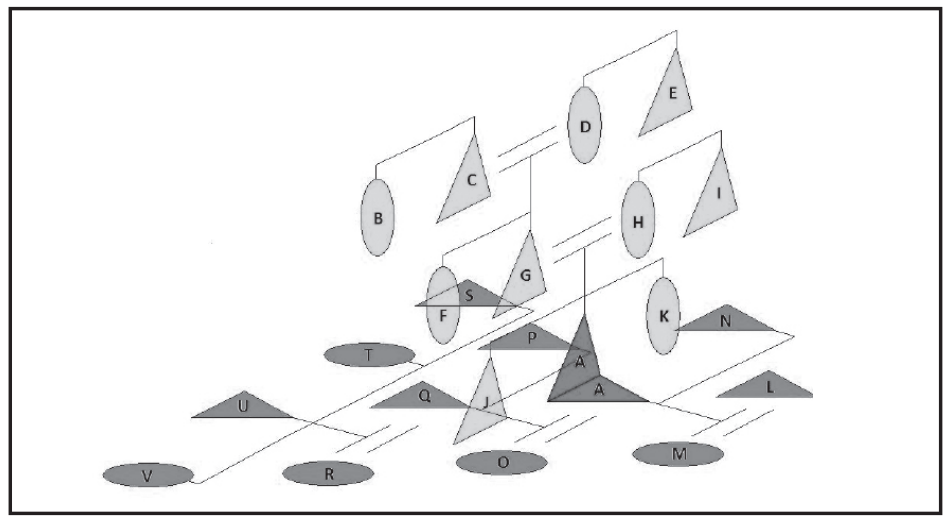

Figura 2: Duplicación parental a partir del sistema laku (elaboración propia) 
Aquí observamos una simplificación de la operación del sistema laku, una vez que éste se libera de la restricción impuesta por su circunscripción a líneas filiales específicas. Consideremos el grupo familiar verde, donde el sujeto $A$ entrega su nombre a un sujeto del grupo amarillo que, mediante el lakutun, también se denomina A. Luego, comenzando desde este don inicial, emerge una duplicación de los vínculos parentales de cada uno de los sujetos. Así, los sujetos L, M, G y $\mathrm{H}$ son ahora padres de ambos $\mathrm{A}$; J y N son sus hermanos; I su tío; O su esposa; $P$ y $Q$ sus hijos, R su nuera; $U$ y $S$ sus nietos, etc. Lo mismo es válido para cada sujeto particularmente, y también es posible considerar las relaciones indirectas. Es decir, por ejemplo, $\mathrm{H}$ puede ser considerada como madre no solo para A verde, sino también para su hermano $\mathrm{N}$, y así sucesivamente.

Todo ese modelo podría considerarse dentro del marco de un parentesco ritual, donde "se emplean términos parentales para crear o simbolizar relaciones entre grupos o individuos particulares dentro de la sociedad, que no están relacionados por aquello que la sociedad normalmente considera como parentesco" (Parkin, 1997, p. 124, traducción propia). En efecto, Foerster sigue esta línea al afirmar que "los vínculos 'nominales' son el intento de 'politizar' algo que puede ser visto y 'tematizado' como vínculos 'naturales'” (2010, p. 106). Sin embargo, no concordamos del todo con esta postura, fundamentalmente por el énfasis que pone en las relaciones de procreación para la definición del parentesco "real" versus el parentesco "metafórico" o "mimético" (Schneider, 1984). De manera diferente, nos parece que para los pewenche los vínculos derivados del lakutun son perfectamente "reales", y de hecho totalmente equivalentes a aquellos derivados de la procreación. Es más, si bien puede existir una diferencia entre los vínculos derivados de relaciones de procreación y los que no los son, esta diferencia no es socialmente significativa. Lo que, si hace una diferencia significativa entre, por así decirlo, gente que es "más pariente" y gente que es "menos pariente", es la distancia espacial y la co-residencia (Course, 2011; González Gálvez, 2016; Isla, 2018).

En la sección anterior reseñamos sucintamente el contexto general de presiones impuestas por el Estado chileno sobre las poblaciones mapuche. En este marco, una imposición fundamental ha sido la de adoptar el sistema de denominación oficial, con patronímicos señalando filiación, y nombres propios escogidos libremente. Esta situación ha generado la ya mencionada aparente disolución del sistema laku en la mayor parte de los territorios mapuche, a excepción de Alto Biobío. Considerando esto, es obvia la pregunta sobre qué es lo que permite la persistencia del sistema laku junto al sistema chileno de denominación en este lugar. Una respuesta obvia para esto sería el hecho efectivo de que el impacto del colonialismo chileno en Alto Biobío ha sido mucho más tardío que en el resto del territorio mapuche, radicalizándose solo a fines del siglo XX (Bonelli \& González Gálvez, 2018; Fuenzalida, 2010). Si bien esta explicación resulta plausible, deja de lado la interrelación práctica de los dos sistemas de denominación. Al respecto, creemos que, si aceptamos primero que el sistema laku tradicionalmente tenía un sesgo hacia la formación de unidades territoriales regidas por un principio filial (Foerster \& Gündermann, 1993; Foerster, 2010; Isla, 2018), sobre todo considerando que el sistema tradicional de denominación mapuche no incluye patronímicos, al introducirse un sistema de denominación como el 
hispano, que implica siempre una marca de filiación bilateral, la única razón de subsistencia que tendría el sistema laku sería la de replicar los roles a ser cumplidos en la vida social. Pero esta posibilidad podría ser descartada de acuerdo a nuestra experiencia etnográfica. El quiebre con la supuesta restricción patrilineal que regía al sistema laku, ${ }^{13}$ en términos de que el nombre puede ser incluso dado a una persona no-mapuche, parece indicar que muy probablemente lo que sucede es que el conjunto de relaciones resultantes del don del nombre son mucho más importantes que los significados atribuidos al nombre en sí mismo. El sistema laku, entonces, ya no tendría tanto que ver con la filiación ni con el traspaso de características personales, sino con la multiplicación y la herencia de relaciones.

En un contexto sudamericano en general, esta herencia relacional, que no está vinculada estrictamente a la procreación, resuena de manera importante con la propuesta de Viveiros de Castro de un estado relacional por defecto en las cosmologías amerindias, denominado como "afinidad potencial". En sus términos, en este estado "es la afinidad la que se posiciona como la dimensión dada de la matriz cósmica relacional, mientras que la consanguinidad cae dentro del ámbito de la acción e intención humanas" (2001, p. 19, traducción propia). En paralelo, en un contexto etnográfico absolutamente distinto, y tomando una posta antes esbozada por Schneider (1984), Janet Carsten $(1997,2000)$ muestra que el parentesco poco y nada tiene que ver con las relaciones derivadas de la procreación, y mucho con las ideas que distintas culturas pueden tener con respecto a lo que son las relaciones. En algunos casos, esta perspectiva implica la necesidad de un proceso de convivencia e intimidad (Overing \& Passes, 2000; Vilaça, 2002), mientras en otro, como podríamos suponer sucede en el caso de las relaciones derivadas del lakutun, la relación se crea en base a una co-relación común con respecto a un tercero (véase Carsten \& Hugh-Jones, 1995). De todas formas, lo importante en ambos casos es la idea de que los parientes no son necesariamente dados, y que en efecto cualquier sujeto, bajo determinadas circunstancias, puede ser transformado en pariente.

Siguiendo hasta cierto punto esta senda, Course $(2008,2011)$ propone que las relaciones sociales tienen un doble rol en consideración de la persona mapuche. Primero, para convertirse en persona, los mapuche deben crear relaciones que van más allá de aquellas que les son dadas por nacimiento. Segundo, respetando el modo igualitario y libre en que los mapuche conciben la vida (Melville, 2016), los sujetos intentan volver todas sus relaciones, tanto las dadas como las construidas, a términos de afinidad. Todo esto tiene importantes implicancias para pensar con respecto al sistema laku, pues, si para los mapuche-pewenche el parentesco es también algo a ser construido en lugar de ser algo simplemente dado, y considerando el comportamiento centrífugo de los sujetos mapuche que tiene la finalidad de afirmar su estatus de persona (Course, 2011), entonces la persistencia del sistema laku puede relacionarse a una mezcla de ambos aspectos. Es decir, el sistema laku tanto construye el parentesco como permite la ampliación instantánea de las relaciones de cada sujeto mapuchepewenche, incluso de aquellos no directamente involucrados en la relación.

Aunque en un sentido estricto esta tesis no es suficiente para explicar la persistencia del sistema laku en Alto Biobío, menos lo sería la 
hipótesis clásica de la filiación. Lo que sí parece claro es que si la importancia del sistema laku se encuentra en relación a las alianzas que el mismo hace emerger -en lugar de encontrarse en la relación entre ambos laku per se-, es también posible sostener que el parentesco ritual derivado del sistema laku crea una suerte de límite relacionado con la afirmación de una mismidad pewenche en su diferenciación con el resto de las poblaciones mapuche, y, por supuesto, winka. Este sentimiento parental es hecho explícito a través de la voz "pariente", que la mayoría de la gente usa en Alto Biobío para referirse a otros mapuche-pewenche al saludarse. Este uso es diferente de la voz "nuestra sangre", empleada en referencia a los mapuche, no-pewenche, de otras áreas geográficas. En efecto, el sistema laku posibilita la imaginación de un colectivo que en términos parentales es absolutamente real. Si los pewenche se llaman mutuamente "pariente", eso es porque, en realidad, eso es lo que son.

\section{Conclusión}

Para concluir mi reflexión, me gustaría regresar al relato con que introduje este artículo, porque hay un dato importantísimo en él que he omitido intencionalmente hasta este momento. Ese dato es que María, la "madre" de Juana, era una mujer chiñurra14, no-mapuche. María, en ese momento, no tenía "nombre mapuche", y su única vinculación parental "real" con el resto de la gente en Cauñikú vendría dada por las relaciones de afinidad que derivan de su matrimonio con un conocido hombre pewenche del sector. No obstante, gracias al sistema laku, María puede convertirse en pariente "consanguineo" del resto, reafirmando una relación de mismidad que ya había sido creada a partir de su residencia continuada en Alto Biobío (Overing \& Passes, 2000; Vilaça, 2002). Esta es, en nuestra impresión, uno de las razones centrales de la persistencia del sistema laku: se adapta estructuralmente para la reafirmación y/o creación de un límite diametral parental/ étnico entre los pewenche y los otros. En la vida mapuche rural, aunque existentes, las referencias a elementos raciales y/o culturales para la delimitación de límites étnicos carece de esencialismo (González Gálvez, 2016). Luego, aunque los sujetos expresen una diferencia en estos términos, la misma puede ser aminorada a través de la convivencia (González Gálvez, 2015). En este caso, esto se ve además reafirmado a través del sistema laku, permitiendo la clasificación de María como pariente, en los múltiples sentidos que puede tener esta voz en Alto Biobío.

Adicionalmente, el sistema laku permite un asunto central a la vida mapuche que ya hemos señalado: la supresión de la jerarquía "natural" derivada de las diferencias generacionales (Melville, 2016). Esto porque, gracias al sistema laku, cada generación "superior" se fusiona con una generación inferior, creando dos pares generacionales cíclicos. Más aún, si lo comparamos con el compadrazgo, tan común en otras partes de Latinoamérica, vemos que en el lakutun hay un principio de identidad que tiene lugar entre los sujetos directamente implicados en el ritual, y no entre "co-(m)padres". Considerando ambos rituales en conjunto, la relación se encuentra invertida: entre los laku emerge una relación signada por la identidad y simetría, mientras que entre los padres y los laku aparece la diferencia y la asimetría. Por el contrario, en el compadrazgo la simetría/identidad tiene lugar entre padres y padrinos, y la diferencia/asimetría entre hijo/ahijado y padres/padrinos. Hasta 
cierto punto, lo que sucede con el donador del nombre es que suprime el potencial de asimetría que podría tener sobre los padres del receptor del nombre, a través del don mismo del nombre. Como resultado, a diferencia de lo que ocurre con el compadrazgo, el sistema laku crea y multiplica relaciones que van más allá de una mera alianza simétrica, que están implicando una torsión dentro de la estructura supuestamente lineal del parentesco pewenche ${ }^{15}$. Luego, la articulación social generada en base al sistema laku produciría una estructura social similar a un ovillo de lana algo enredado, lejos de los linajes imaginados durante años para dar forma a la sociedad (Faron, 1961a).

Por último, nos parece que contemporáneamente el sistema laku, con toda la flexibilidad que conlleva, permite mantener un sentido de red que existe imaginariamente entre los mapuche-pewenche, y que, en términos paren-

\section{Notas}

${ }^{1}$ Teniendo en consideración la literatura etnográfica contemporánea, mi propia experiencia etnográfica en sectores costeros de Arauco, y la de otros investigadores en sectores meridionales de la región de la Araucanía y Los Ríos, no hay reportes de la persistencia de este sistema en otros lugares distintos a este sector. El trabajo de campo en que se basa este artículo fue realizado durante el primer semestre de 2008, en las comunidades de Callaqui y Cauñikú.

${ }^{2}$ Con esto es posible tensionar ciertas teorías que sostenían que, en la transmisión del nombre, se jugaba la transmisión de cierta substancia de linaje, Ilamada küga (Augusta, 1907; Latcham, 1924; Silva, 1984).

${ }^{3}$ Como la alianza mapuche es matrilateral, la circulación de mujeres entre linajes conllevaría la circulación de nombres femeninos: para encontrar una donante de nombre, una mujer debería observar hacia una mujer de la generación alterna superior en su linaje de origen, que es totalmente diferente del linaje donde se casará.

${ }^{4}$ Es interesante notar que, coincidentemente, en otros grupos indígenas sudamericanos, sobre todo en Brasil Central, es justamente el nombre lo que entrega a la persona su lugar en el mundo social (Bamberger, 1974; Ewart, 2013; Lea, 1992) tales, por las razones que hemos delineado, tiene un fundamento absolutamente real. Este sentido de red permite la extrapolación de un colectivo limitado, diferente no solo de los no-mapuche, sino también del resto de poblaciones mapuche, localizado y enraizado en el corazón de la cordillera.

\section{Agradecimientos}

Este artículo fue escrito con el apoyo del Centro de Estudios Interculturales e Indígenas (CIIR, Conicyt/Fondap/15110006). Agradezco especialmente a Nicsia Alegría, Pedro Aguilera, Lucinda Antil, y Nolfa Pavián por compartir parte de sus vidas y conocimientos conmigo. También me gustaría agradecer a Ana Ancapi, con quien realicé varias estancias de trabajo de campo sobre las cuales se basa este trabajo.

\footnotetext{
${ }^{5}$ Véase Braroe (1975), para una aproximación similar sobre el empleo de nombres indígenas frente a la imposición burocrática de "nombres legales".

${ }^{6}$ Hay diversas formas mapuche para averiguar sobre el destino de las personas. Sobre ellas, y la importancia que tiene esta indagación, véase Course (2014).

${ }^{7}$ La misma Inez Hilger (2015) señala que, en algunos casos, era posible incluso cambiar el nombre de un niño, por ejemplo, ante la visita circunstancial de un líder connotado.

${ }^{8}$ Sobre los sentidos de la sangre entre los pewenche, véase Bonelli (2014).

${ }^{9}$ Una idea similar a la "compresión" del linaje ha sido trabajada de manera interesante por Ana Ramos (2010), para los mapuche del lado argentino.

${ }^{10}$ El sentido de la noción "mapuche" dentro de la vida mapuche rural ha sido discutido por distintos etnografos (Course, 2011; Faron, 1961a; Foerster, 2004; Isla, 2018). Véase particularmente González Gálvez (2016).

${ }^{11}$ Acerca de las particularidades de la adscricpión étnica y su vinculación con las políticas censales, véase Gündermann, Vergara
} 
\& Foerster (2005)

${ }^{12}$ La explicación de esto se encuentra parcialmente en la manera en que los mapuche conciben el conocimiento, como una empresa estrictamente personal que se desarrolla a lo largo de la vida (González Gálvez, 2015).

${ }^{13} \mathrm{La}$ inexistencia de esta regla no implica que no se pueda tener una relación de laku al interior de una patrifamilia. En efecto, una

\section{Referencias bibiográficas}

Augusta, F. J. (2002 [1907]). ¿Cómo se llaman los araucanos? Bahía Blanca: Universidad Nacional del Sur.

Bamberger, J. (1974). Naming and the transmission of status in a central Brazilian society. Ethnology 13(4), 363-378.

Barth, F. (comp.) (1969). Ethnic groups and boundaries. The social organization of difference. Oslo: Universitetsforlaget.

Bodenhorn, B. (2000). 'He used to be my relative': exploring the bases of relatedness among Iñupiat of northern Alaska. En Carsten, J. (Ed.), Cultures of relatedness. New approaches to the study of kinship (pp. 128-148). Cambridge: Cambridge University Press.

Bodenhorn, B. \& Von Bruck, G. (2006). The anthropology of names and naming. Cambridge: Cambridge University Press.

Bolton, R. \& Mayer, E. (eds.) (1977). Andean kinship and marriage. Washington: American Anthropological Association.

Bonelli, C. (2014). What Pehuenche blood does: hemic feasting, intersubjective participation, and witchcaft in Southern Chile. Hau: Journal of Ethnographic Theory 4 (1), 105-127. DOI: https://doi. org/10.14318/hau4.1.004

(2012). Ontological disorders: nightmares, psychotropic drugs and evil spirits in southern Chile. Anthropological Theory 12 (4): 407-426. DOI: 10.1177/1463499612469587

Bonelli, C. \& González Gálvez, M. (2018). The roads of immanence: Infrastructural change in Southern Chile. Mobilities 13 (4). DOI: 10.1080/17450101.2017.1388346

Braroe, N. (1975). Indian and White: Self-Image and interaction in a Canadian Plains Community. Stanford: Stanford University Press.

Carsten, J. (2004). After kinship. Cambridge: Cambridge University Press.

(2000). Cultures of relatedness. New approaches to the study of kinship. Cambridge: Cambridge University Press.

(1997). The heat of the heart. The process of kinship in a

Malay fishing community. Oxford: Oxford University Press.

Carsten, J. \& Hugh-Jones, S. (eds.) (1995). About the house: Levi-Strauss and beyond. Cambridge: Cambridge University Press.

Coña, P. (2002 [1930]). Testimonio de un cacique mapuche. Santiago: Pehuén.

Correa, M. \& Mella, E. (2010). Las razones del illkun/enojo: Memoria, despojo y criminalización en el territorio mapuche de Malleco. Santiago: Lom.

Course, M. (2014). The end of me: Mapuche narratives of destiny. persona puede tener cualquier laku, en tanto éste tenga una "edad consciente".

${ }^{14}$ El femenino de winka. Derivaría de la voz castellana señora.

${ }^{15}$ Véase Isla (2018) para una crítica sobre la aplicación del concepto de linaje entre poblaciones mapuche.

En Oakdale, S. \& Course, M. (eds.), Fluent selves: autobiography, person and history in Lowland South America (pp. 144-164). Lincoln: University of Nebraska Press.

(2011). Becoming Mapuche: person and ritual in indigenous Chile. Urbana: University of Illinois Press.

(2005). Borges, the Mapuche, and the mother's brother's son. Cambridge anthropology 25 (1), 11-30.

Ewart, E. (2013). Space and society in central Brazil: a Panará ethnography. London: Bloomsbury.

Faron, L. (1961a). Mapuche social structure: institutional reintegration in a patrilineal society of central Chile. Urbana: University of Illinois Press.

(1961b). The Dakota-Omaha continuum in Mapuche society. Journal of the Royal Anthropological Institute 91 (1), 11-22. (1956). Araucanian patri-organization and the Omaha system. American Anthropologist 58, 435-456.

Fernández, F. \& Ojeda, D. (2015). Criminalización de la resistencia mapuche como política del miedo. Atenea Digital 15 (4), 267-277.

Foerster, R. (2010). Acerca de los nombres de las personas (üy) entre los mapuches. Otra vuelta de tuerca. Revista Chilena de Antropología 21, 81-110.

(2004). ¿Pactos de sumisión o actos de rebelión? Una aproximación histórica y antropológica a los mapuches de la costa de Arauco, Chile. Tesis doctoral. Leiden: University of Leiden.

(1980). Estructura y funciones del parentesco mapuche: su pasado y presente. Tesis de licenciatura. Santiago: Universidad de Chile.

Foerster, R. \& Gündermann, H. (1993). Acerca del nombre propio mapuche. Nütram IX (31), 41-58.

Fuenzalida, D. (2010). Aproximaciones a la significación espacial de los pewenche relocalizados en Ayin Mapu. Tesis de licenciatura. Santiago: Universidad de Chile.

González, H. (1986). Propiedad comunitaria o individual. Las leyes indígenas y el pueblo mapuche. Nütram 3, 7-13.

González, M. (2016). Los mapuche y sus otros: Persona, alteridad y sociedad en el sur de Chile. Santiago: Editorial Universitaria. (2015). The truth of experience and its communication: reflections on Mapuche epistemology. Anthropological Theory 15 (2), 141-157. DOI: 10.1177/1463499614560947

Gudeman, S. (1971). The compadrazgo as a reflection of the 
natural and spiritual person. Proceedings of the Royal Anthropological Institute of Great Britain and Ireland 1971, 45-71.

Gündermann, H., Vergara, J. \& Foerster, R. (2005). Contar a los indígenas en Chile. Autoadscripción étnica en la experiencia censal de 1992 y 2002. Estudios Atacameños 30, 91-115.

Hilger, I. (2015). Infancia, vida y cultura mapuche. Santiago: Pehuén.

Isla, J. A. (2018). Un lieu dans le monde: Personne et société chez les pewenche. Tesis doctoral. Paris: EHESS [Manuscrito].

Latcham, R. (1924). La organización social y las creencias religiosas de los antiguos araucanos. Santiago: Imprenta Cervantes.

Lea, V. (1992). Mebengokre (Kayapo) onomastics: a facet of houses as total social facts in central Brazil. Man 27 (1), 129-153.

Leinaweaver, J. (2007). On moving children: the social implications of Andean child circulation. American Ethnologists 34 (1): 163-180. DOI: 10.1525/ae.2007.34.1.163.

Lévi-Strauss, C. (1969). The elementary structures of kinship. $2^{\text {nd }}$ ed. London: Eyre \& Spottiswoode.

Mauss, M. (1985). The category of the human mind: the notion of person; the notion of self. En Carrithers, M., Collins, S. \& Lukes, S. (eds.), The category of the person (pp. 1-25). Cambridge: Cambridge University Press.

Maybury-Lewis, D. (ed.) (1979). Dialectical societies: The Gê and Bororo of central Brazil. Cambridge: Harvard University Press.

Melville, T. (2016 [1976]). La naturaleza del poder social mapuche. Santiago: Pehuén.

Millalén, J. (2006). La sociedad mapuche prehispánica: Kimün, arqueología y etnohistoria. En Mariman, P., Caniuqueo, S., Millalén, J. \& Levil, R., j...Escucha, winka...! (pp. 17-52). Santiago: Lom. Namuncura, D. (1999). Ralco ¿represa o pobreza? Santiago: Lom.

Overing, J. \& Passes, A. (2000). The anthropology of love and anger: the aesthetics of conviviality in native Amazonia. London: Routledge.

Parkin, R. (1997). Kinship: an introduction to basic concepts. Oxford: Blackwell.

Ramos, A. M. (2010). 'The good memory of this land': Reflections on the processes of memory and forgetting. Memory Studies 3 (1), 55-72. DOI: $10.1177 / 1750698009348301$

Rivière, P. (1984). Individual and society in Guiana. Cambridge: Cambridge University Press.

Sahlins, M. (2013). What kinship is... and is not. Chicago: University of Chicago Press.

Schneider, D. (1984). A Critique of the study of kinship. Ann Arbor: University of Michigan Press.

Silva, O. (1984). En torno a la estructura social de los mapuches prehispánicos. CUHSO 1, 89-115.

Stuchlik, M. (1976). Life on a half share: mechanisms of social recruitment among the Mapuche of southern Chile. New York: St Martin's Press.

Suzman, S. (1994). Names as pointers: Zulu personal naming practices. Language in Society 23 (2), 253-272.

Thomson, D. (1946). "Names and naming in the Wik Monkan tribe. Journal of the Royal Anthropological Institute of Great Britain and Ireland 76 (2), 157-168.

Vilaça, A. (2002). Making kin out of others in Amazonia. Journal of the Royal Anthropological Institute 8, 347-366.

Villalobos, S. (1989). Los pehuenches en la vida fronteriza. Santiago: Ediciones Universidad Católica.

Viveiros de Castro, E. (2001). Gut feelings about Amazonia: potential affinity and the construction of sociality. En Rival, L. \& Whitehead, N. (eds.), Beyond the visible and the material: the Amerindianization of society in the work of Peter Riviere (pp. 19-43). Oxford: Oxford University Press.

(1992). From the enemy's point of view. Chicago: University of Chicago Press.

Woodrick, A. (1995). Mother-daughter conflict and the selection of ritual kin in a peasant community. Anthropological Quarterly 68 (4), 219-233.

Zavala, J. M. (2008). Los mapuches del siglo XVII. Dinámica interétnica y estrategias de resistencia. Santiago: Editorial Universidad Bolivariana. 